\title{
A rod-type creepmeter for measurement of displacement in active fault zone
}

\author{
Jian-Cheng Lee ${ }^{1}$, Fu-Shu Jeng ${ }^{2}$, Hao-Tsu Chu ${ }^{3}$, Jacques Angelier ${ }^{4}$, and Jyr-Ching $\mathrm{Hu}^{5}$ \\ ${ }^{1}$ Institute of Earth Sciences, Academia Sinica, P. O. Box 1-55, Nankang, Taipei, R.O.C., Taiwan \\ ${ }^{2}$ Department of Civil Engineering, National Taiwan University, Taipei, R.O.C., Taiwan \\ ${ }^{3}$ Central Geological Survey, P. O. Box 968, Taipei, R.O.C., Taiwan \\ ${ }^{4}$ Tectonique Quantitative, Departement de Geotectonique and ESA 7072, Universite P.-\&-M. Curie, Paris, France \\ ${ }^{5}$ The Institute for Secondary School Teacher of Taiwan, Taichung, R.O.C., Taiwan
}

(Received November 2, 1999; Revised February 28, 2000; Accepted February 28, 2000)

\begin{abstract}
A creepmeter has been developed to monitor gradual displacements of near-surface movement in an active fault zone. This rod-type creepmeter is a robust, low-cost instrument that is simple to construct and install. This creepmeter consists of two 3-m invar rods attached to anchored steel piers at each end, straddling the surface traces of active fault. The invar rods are supported by a pair of U-shaped solid steel girders. A mechanical dial-gauge sensor in the middle of the creepmeter is adopted to record the displacement of fault creep, and has a precision of $0.01 \mathrm{~mm}$. Because the creepmeter is installed on the surface, the temperature effect is important. To calibrate and correct for the temperature effect, we carried out hourly measurements over a period of 30 hours to calculate the thermal expansion coefficients for each creepmeter. Thermal corrections could thus be made when readings were taken. Five of these creepmeters have been installed in the Chihshang active fault zone of eastern Taiwan, in the present collision suture zone between the Philippine Sea plate and the Eurasian plate. Readings taken over one year have shown that this rod-type creepmeter is effective in providing a near-continuous record of active fault creep with a good precision.
\end{abstract}

\section{Introduction}

Fault creep is movement of a fault that occurs gradually without generating detectable earthquakes. It differs from the brittle rupture of a fault that generates earthquakes in that it occurs slowly. However, some relationships exist between fault creep and earthquakes. For instance, creep rate changes on a fault are often related to the occurrence of earthquakes. Sometimes abnormally low creep rates take place before the occurrence of major earthquakes (Burford, 1976; Raleigh et al., 1979), and high creep rates occur during or soon after earthquakes (Tocher, 1960; Burford et al., 1973; Mavko, 1982; Schulz et al., 1982).

Creepmeters have commonly been used for monitoring of active fault creep (Nason et al., 1974; Goulty et al., 1979). Installing the creepmeters across an active fault zone allows one to characterize the movement of the fault creep and to determine the relationship between fault creep and earthquakes. Several case studies along the San Andreas Fault in central California (Schulz et al., 1982) have shown that the creepmeter is useful for understanding active fault behavior.

The Longitudinal Valley Fault of eastern Taiwan is an active fault located in the present suture zone between the Philippine Sea plate and the Eurasian plate (Suppe, 1984; Ho, 1986; Tsai, 1986). Continuous fault creep of the Longitudinal Valley Fault during the last 20 years at a rate of $20-30 \mathrm{~mm} / \mathrm{yr}$ has been clearly revealed by geodetic analy-

Copy right (C) The Society of Geomagnetism and Earth, Planetary and Space Sciences (SGEPSS); The Seismological Society of Japan; The Volcanological Society of Japan; The Geodetic Society of Japan; The Japanese Society for Planetary Sciences. ses based on trilateration networks (Yu and Liu, 1989; Yu et al., 1990; Lee and Angelier, 1993) and GPS measurements (Yu et al., 1997), as well as by geological in-site investigation (Lee, 1994; Angelier et al., 1997). The Longitudinal Valley Fault thus provides a good opportunity to study fault creep behavior and its relation to earthquakes. In-site surveys at several sites have been used to determine the amount of creep over intervals of around 6-8 months (Angelier et al., 1997 and 1999). However, the detailed evolution of fault creep, including seasonal variations that were suspected at some localities where measurements were performed twice a year, remained unclear. There was an obvious need for more frequent measurements of the fault displacement. For this reason, we thus designed a specific rod-type creepmeter, by taking both the local geology and the surface conditions into account, in order to record the movement of the active Longitudinal Valley Fault with five creepmeters at two sites near Chihshang.

In this paper, we first present the principles of the operation system of the creepmeter. We then describe the instrumentation, the installation, and the data calibration. The Chihshang Fault case study is used as an example to illustrate the performance of this creepmeter.

\section{Design Concepts}

Creepmeters are common instruments (typically a wire or rod extensometer of 5- to 20-m length) for periodic or continuous measurement of fault creep (Smith and Wyss, 1968; Nason, 1971; Burford et al., 1973; Goulty and Gilman, 1978; Goulty et al., 1978; Schulz et al., 1982). Creepmeters 


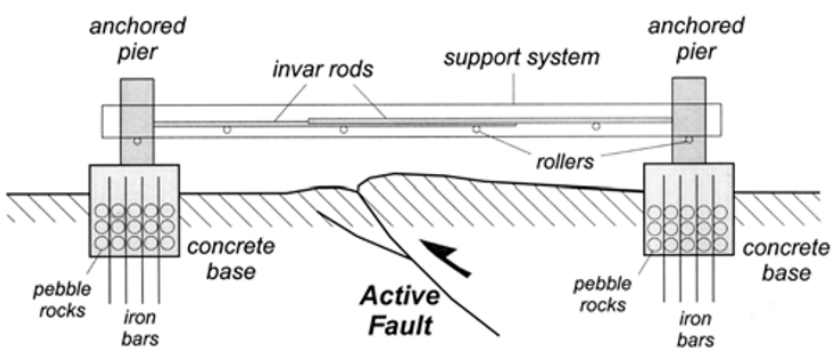

Fig. 1. Schematic representation of the rod-type creepmeter across an active fault. The instrument measures the horizontal relative displacement between the anchored piers on the opposite sides of the active fault.

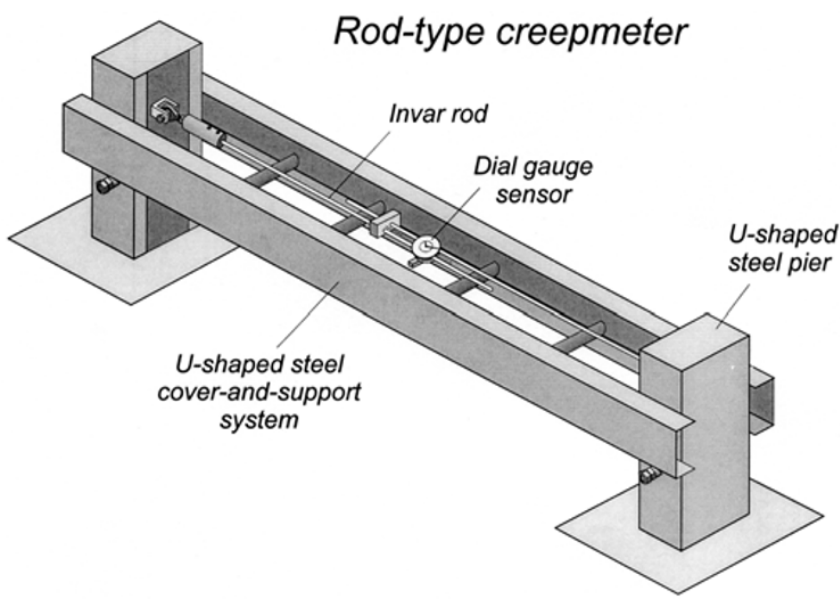

Fig. 2. Details of the rod-type creepmeter installed in the Chihshang active fault zone. The creepmeter is composed of four main parts: the piers, the invar rods, the cover-and-support system, and the dial gauge sensor. The pier is made of U-shaped steel. Each of two parallel invar rods is attached to the piers. The cover-and-support system is made of two U-shaped steel girders rest on the anchored piers.

are installed across active fault traces at chosen angles to the fault strike. Depending on the instrument orientation and on the geometry of the relative displacement, the fault slip may cause the distance between piers to either increase or decrease.

We have developed a relatively simple and low-cost model of rod-type creepmeter (Fig. 1) in order to monitor movements on active faults. Other types of rod creepmeter, such as those in California, have been successfully used in an active fault zone (Nason et al., 1974). The general aspect is shown in Fig. 2, the upper plates that protect the instrument from rainfall being removed to show the rods and sensor. Our creepmeter consists of two invar alloy rods $(62 \% \mathrm{Fe}, 36 \%$ $\mathrm{Ni}$ ), which attached with universal joints (cardan-like) to the firmly anchored piers at each end of the creepmeter. The rods are supported and housed by two rigid U-shaped steel girders that rest on rollers at each pier. The displacement between the two anchored piers can thus be reliably recorded by a mechanical dial gauge sensor, which is mounted between the invar rods in the middle of the instrument.

The creepmeters are installed across the surface traces of the active fault. Unlike most of the creepmeters in California, which are buried in sub-surface housing, we installed the instrument at the surface in order to avoid ground water effects
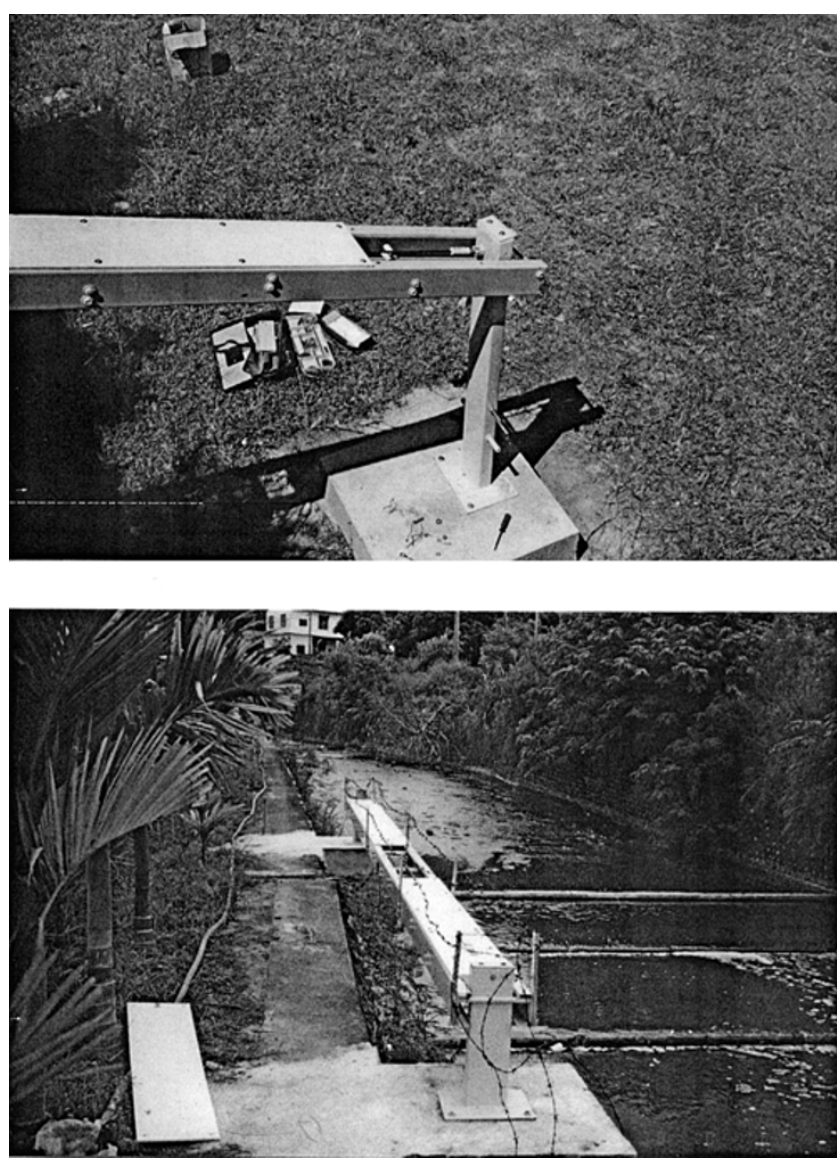

Fig. 3. Two different types of the surface installation of the base of the creepmeter. Upper figure: installation type I, concrete bases are planted vertically on the surface by digging a $0.5-\mathrm{m}$ deep hole. Lower figure: installation type II, concrete bases are horizontally fixed on the water channel's wall.

and soil disturbance. Another advantage of the creepmeter on the ground is that it is easy to access and to maintain. Each creepmeter has to be long enough to cross a single surface fault trace within the whole fault creep zone. At one site, where movement occurs across a wider zone, we had to use two connected and aligned creepmeters to measure the total displacement.

The main advantages of our instrument lie in its simplicity, low-cost, and robustness. This type of creepmeter (Figs. 1 and 2) is rather simple to build and easy to install. The measurements, which have already been carried out for more than one year, indicate that wind and rain do not have any significant direct effect on the instrument. The main disadvantages of the instrument lie in its sensitivity to temperature, the limitation on its length, and friction within the instrument. Because the instrument is exposed to the sunshine, the temperature effect cannot be avoided. Thus, careful correction and calibration for the temperature effect are indispensable. Within certain bounds, the limitation on length is a common characteristic of mechanical creepmeters. The friction affecting the movement of the invar rods comes mainly from the contacts between the rods, the housing, the rollers, and the piers. Both the preliminary mechanical test and subsequent records of displacement suggested that their role can be negligible. 

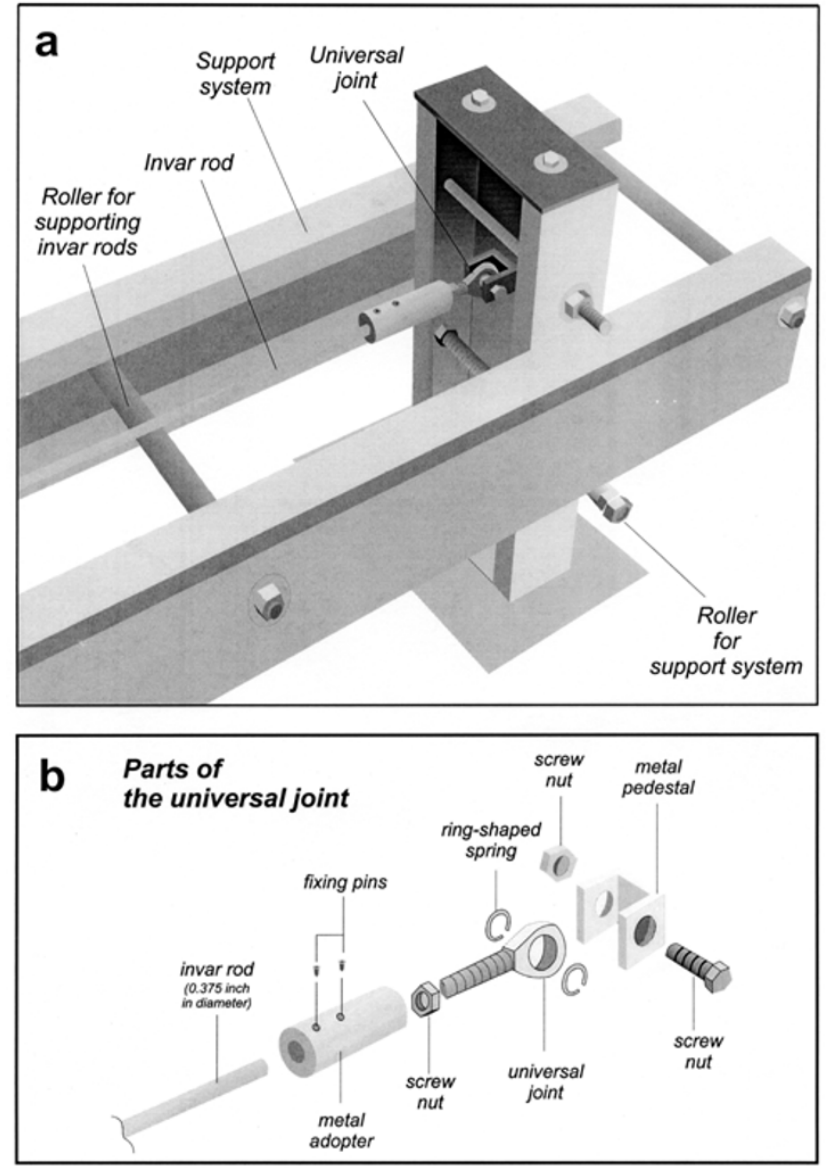

Fig. 4. Details of the extremity part of the creepmeter. (a) The invar rods are attached on each pier by a universal joint and are supported by the rollers on the U-shaped steel support system. The support system with two parallel U-shaped steel girders straddles on the piers and can move freely on the supported rollers on piers. (b) Detailed parts of the universal joint linking between the invar rods and the piers.

\section{Description of the Instrument \\ 3.1 Pier and base}

The piers at each end of the instrument are made from lengths of U-shaped steel girders (Fig. 3) from 50-cm height (for flat places) to 100-cm height (for slopes). The piers were mounted on $60-\mathrm{cm} \times 60-\mathrm{cm}$ wide concrete bases. Two kinds of concrete base have been adopted. For surface installation (Fig. 3a), a 50- to 60-cm deep cavity is dug in the soil and filled with concrete, iron bars and pebbles (Fig. 1). The iron bars are more than $1 \mathrm{~m}$ long and are thus implanted deeper than the concrete base so that they significantly improve the mechanical coupling with the surrounding earth. In the case of the Chinyuan water channel, the creepmeters were not installed directly in the soil, but attached to the thick wall of the channel. Two creepmeters were installed on the wall of the channel and one creepmeter was installed on the inside of the channel (Fig. 3b) in order to avoid obstructing the pathway on the top of the dyke wall. In all cases, the concrete bases were constructed four months before the installation of the creepmeter.

\subsection{Rod creepmeter}

The main part of the rod-type creepmeter (Fig. 2) consists of two parallel invar rods, a support-and-cover system, and a

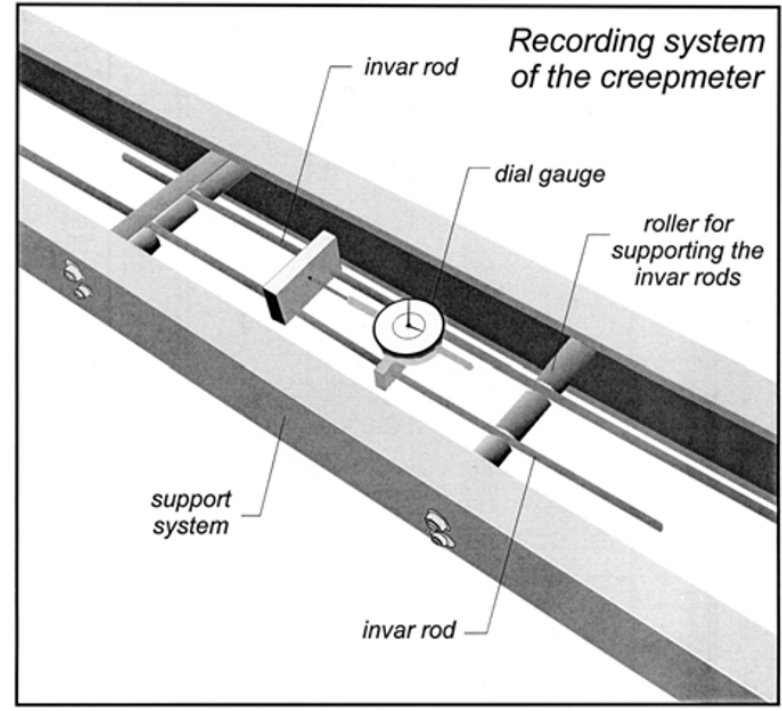

Fig. 5. Details of the recording system in the middle part of the creepmeter. The relative horizontal movement of two invar rods can be measured by a mechanical dial gauge sensor, with a precision of $0.01 \mathrm{~mm}$ and a range of $50 \mathrm{~mm}$.

recording system. The invar rods are 3- to 4-m long and 9.52 $\mathrm{mm}(0.375 \mathrm{inch})$ in diameter. Each invar rod was attached to the firmly anchored steel pier at one end by a universal joint (Fig. 4). The universal joints allow the invar rods to keep moving freely when shortening, lengthening or rotation occurred between the two piers. Undesirable effects of deformation are thus minimized. An important part of the design for any rod-type creepmeter is to support the rods so that they are free to move along their own axes but not sideways (Agnew, 1986). For this, we let the parallel invar rods lie on the rollers fixed to the support-and-cover system (Figs. 4 and 5). The support-and-cover system is composed of two parallel U-shaped steel girders, which straddle the two piers (Fig. 4). Rollers fixed to the steel piers allow the support-and-cover system to move horizontally when creep occurs between the two piers. The cover is made of light plastic plates to protect the instrument from rain and sunshine. In the middle of the instrument, we mounted a mechanical dial-gauge (Fig. 5) for measuring the relative displacement (shortening or lengthening) between the parallel free ends of the two invar rods.

\subsection{Dial gauge sensor}

We use a dial gauge sensor to record the displacement due to fault creep. A mechanical dial gauge was adopted in our creepmeter design for two reasons. First, such a gauge is largely accurate enough for our purpose; second, because its simpler construction, the probability of malfunction events is reduced, in comparison with more sophisticated devices (an important factor to consider taking the environment of our creepmeters into account). The mechanical dial gauge that we used is commonly adopted for measuring displacements in civil engineering. It is easy to install and enable one to take the readings with a good precision. Two metal plates fixed on each invar rod in the middle of the instrument (Fig. 5). We mounted the dial gauge on one metal plate and kept the detector tube of the dial gauge in contact with the other metal 


\section{Daily Fluctuation of Readings on Creepmeter due to Temperature Effect}
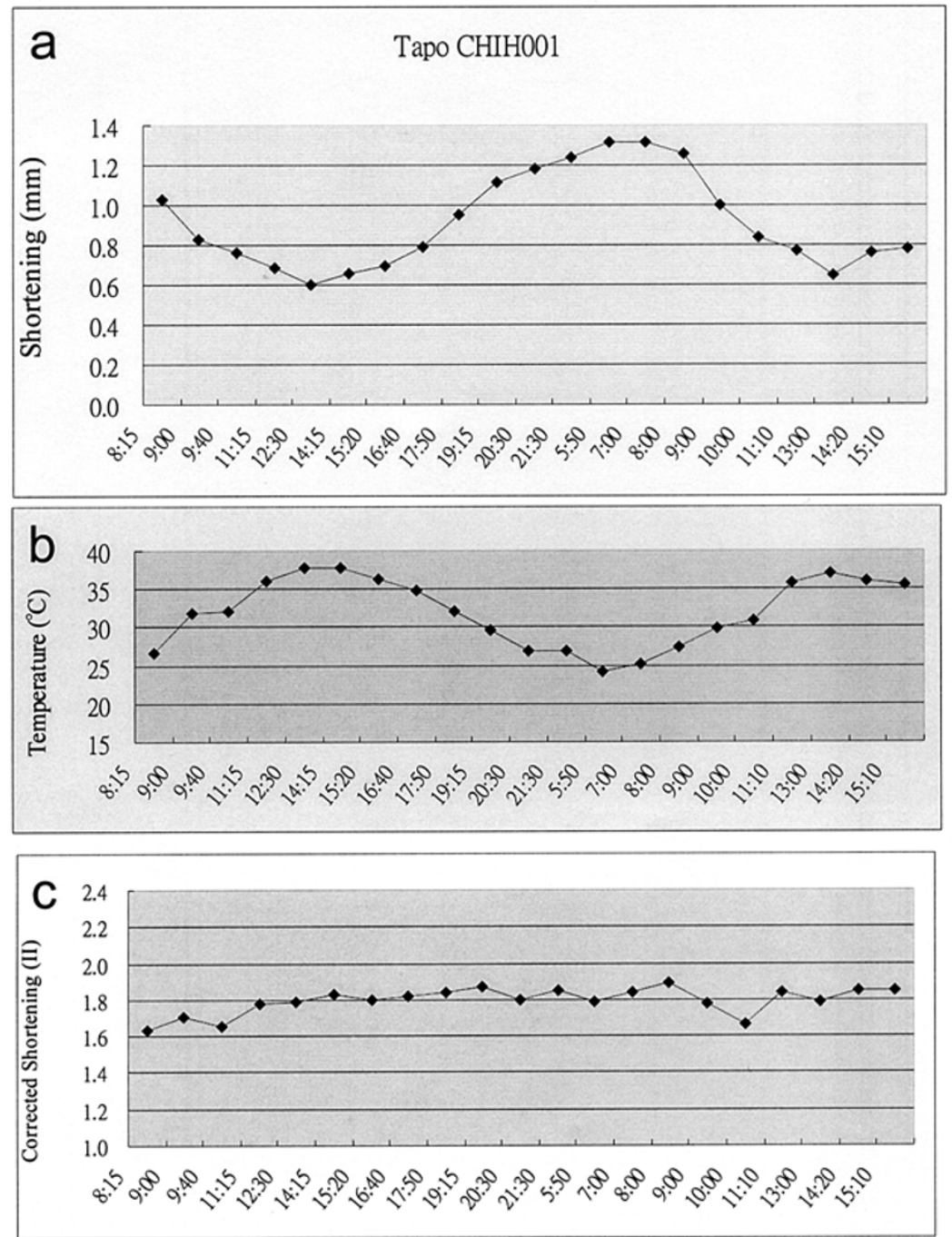

Fig. 6. Variation of the measured shortening displacement with the temperature. The curves of the shortening (a) and of the temperature (b) versus time are deduced from a 30-hour run of hourly measurements. The variation indicates that the displacement (shortening amount) is basically a function of the temperature. The data calibration and correction have been carried out on this basis (see text for the details). (c) The plot of corrected shortening amount with respect to time. The flat curve with a small fluctuation indicates that the calculation is adequate.

Table 1. Parameters of the temperature effect and results of calculated thermal-expansion coefficients deduced from hourly measuring experiments over a period of 30 hours. Such calibration is illustrated in Fig. 6 for one of the creepmeters (CHIH001). The range of temperature represents the minimum and the maximum temperatures during the experiments. The difference of shortening represents the difference between the maximum and the minimum data readings during the same period. The thermal-expansion coefficients for each creepmeter are calculated based on three parameters list in the table and Eq. 1.

\begin{tabular}{ccccc}
\hline $\begin{array}{c}\text { Name of } \\
\text { creepmeter }\end{array}$ & $\begin{array}{c}\text { Range of } \\
\text { temperature }\left({ }^{\circ} \mathrm{C}\right)\end{array}$ & $\begin{array}{c}\text { Difference of } \\
\text { shortening }(\mathrm{mm})\end{array}$ & $\begin{array}{c}\text { Lengths of } \\
\text { invar rods }(\mathrm{mm})\end{array}$ & $\begin{array}{c}\text { Thermal-expansion } \\
\text { coefficient }\left(/{ }^{\circ} \mathrm{C}\right)\end{array}$ \\
\hline CHIH001 & $24.2-37.9$ & 0.71 & 6020 & $8.6 \times 10^{-6}$ \\
CHIH002 & $24.3-37.2$ & 0.52 & 7300 & $5.5 \times 10^{-6}$ \\
CHIH003 & $23.6-41.5$ & 0.54 & 7310 & $4.1 \times 10^{-6}$ \\
CHIH004 & $21.55-35.0$ & 0.85 & 5820 & $10.8 \times 10^{-6}$ \\
CHIH005 & $24.4-39.3$ & 0.755 & 7290 & $7.0 \times 10^{-6}$ \\
\hline
\end{tabular}




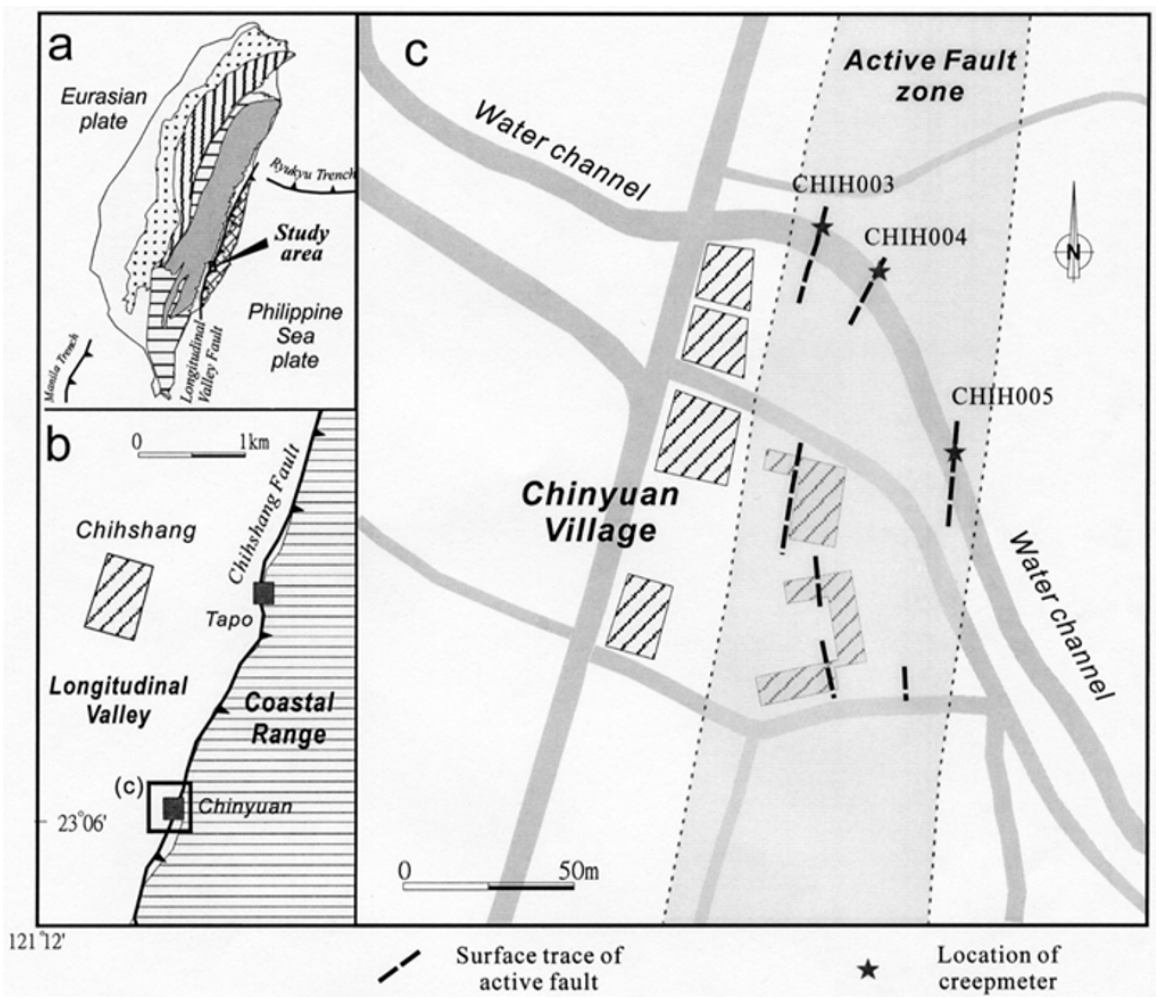

Fig. 7. Location of the sites of the creepmeters in the Chihshang active fault area. (a) The Chihshang Fault is an active segment of the Longitudinal Valley Fault, which represents the present collision suture between the Philippine Sea plate and the Eurasian plate. (b) The creepmeters at Chinyuan site are situated on the Chihshang active fault zone, along which the Coastal Range thrusts onto the Longitudinal Valley. (c) Location of the creepmeters and the surface traces of active fault at the Chinyuan site. Three creepmeters have been installed on the wall of the water channel and across the three surface traces of active fault within an about 100-m wide active fault zone.

plate. The relative movement of the two parallel invar rods along their axis can thus be measured and recorded directly by simple readings on the dial gauge. The dial gauges used are standard metric gauges manufactured by the Mitutoyo Company, and they cover a $0-50 \mathrm{~mm}$ range, with a precision of $0.01 \mathrm{~mm}$.

\subsection{Thermometer}

The temperature of the invar rods is manually recorded when the readings of the dial gauge are taken. We use a common digital thermometer with an accuracy of $0.1^{\circ} \mathrm{C}$. The thermometer with a detector bar allows to measure the temperature of the invar rods. The temperature of the invar rods and the outdoor temperature are both recorded at the time each dial gauge reading is made. The temperature measurements allowed us to carry out systematic data calibration and correction for the temperature effect. This temperature calibration is discussed in more detail in the next section.

\section{Data Calibration}

Because the creepmeter is basically composed of metal materials and exposed to the sun, the effect of thermal expansion requires consideration although a low thermal expansion material (invar alloy) is used for the rods. The temperature effect has been evaluated by taking hourly measurements over a period of 30 hours. The apparent lengthening in the middle of the day is due to thermal expansion. The data plotted in Fig. 6 illustrate the daily fluctuation for the creepmeter CHIH001. During one day, with a temperature variation of $13.7^{\circ} \mathrm{C}$ (between $24.2^{\circ} \mathrm{C}$ and $37.9^{\circ} \mathrm{C}$ ), we obtained an appar- ent displacement of $0.71 \mathrm{~mm}$ for the creepmeter CHIH001. We used the data of such experiments as the basis for statistical temperature calibration. Under the reasonable assumption that during one day the apparent displacements principally depend on the variation in temperature, the thermal expansion coefficient (c) of creepmeter can be represented as follows:

$$
c=\left(D_{1}-D_{2}\right) /\left[L \times\left(T_{1}-T_{2}\right)\right]
$$

where $D_{1}$ is the measured displacement of creepmeter at temperature $T_{1}, D_{2}$ is the measured displacement at temperature $T_{2}$, and $L$ is the length of the invar rods. The thermal expansion coefficients for each creepmeter can thus be calculated (Table 1). Based on Eq. 1, the dial gauge readings can be corrected to a chosen reference temperature to determine the amount of displacement due to fault creep.

\section{Observation}

We have installed five creepmeters at two sites, Tapo and Chinyuan, in the Chihshang active fault zone (Fig. 7). The Chihshang Fault is situated in the Longitudinal Valley, a present collision suture between the Philippine Sea plate and the Eurasian plate in eastern Taiwan. At the Tapo School site, we connected two creepmeters across a 10-m wide fault zone at the foot of a gentle hill slope. At the Chinyuan water channel site, a nearly flat area, we set up three creepmeters straddling three observed surface traces of active fault in a 100-m wide zone (Fig. 7). The orientations of the creepmeters are 

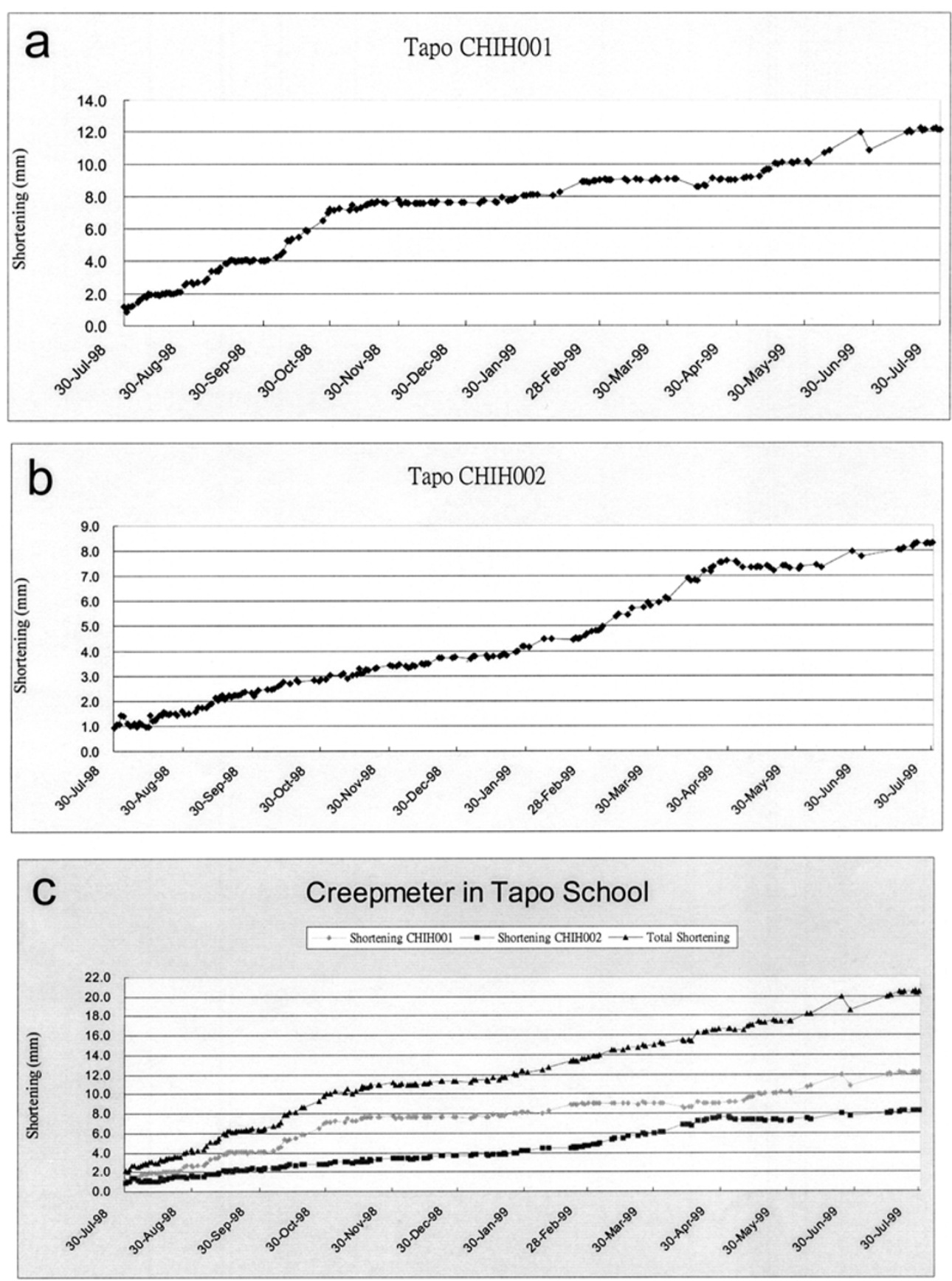

Fig. 8. One-year creep data (August 1998-July 1999) at Tapo elementary School. The fault creep is represented by the shortening versus the time. Two creepmeters, $\mathrm{CHIH001}$ and $\mathrm{CHIH002}$, are connected together to measure the fault creep in an about 10-15 m wide active fault zone located at the foot of a small hill. (a) Creep data of creepmeter CHIH001. (b) Creep data of creepmeter CHIH002. (c) The total shortening amount of the creepmeters represented by the sum of the data of two creepmeters.

set to be parallel, or at a small angle, to the general trend of the relative displacement vectors between either side of the Chihshang Fault (Angelier et al., 1999), in order to measure the horizontal shortening due to fault creep. The Tapo creepmeters (CHIH001 and $\mathrm{CHIH002)}$ trend $\mathrm{N} 115^{\circ} \mathrm{E}$. The three Chinyuan creepmeters CHIH003, CHIH004, and CHIH005 trend $\mathrm{N} 113^{\circ} \mathrm{E}, \mathrm{N} 156^{\circ} \mathrm{E}$, and $\mathrm{N} 164^{\circ} \mathrm{E}$, respectively.

The concrete bases of the creepmeters were constructed in March 1998. The instruments were not installed until July 1998 to allow sufficient time for concrete strengthening and ground settlement. The creep data have been recorded since July 30, 1998. We took creep readings on a daily basis for the first two months and then several times weekly. Readings are made at about 4 to 6 p.m. (soon before sunset) in order to minimize the temperature variations. In this paper, we present the first year data from the creepmeters in the Chihshang active fault zone for the period August 1998 to July 1999.

Figure 8 shows displacement due to fault creep (shortening) versus time at the Tapo School site, recorded by two aligned and connected creepmeters, CHIH001 and CHIH002. The plots illustrate that the fault is continuously creeping. 

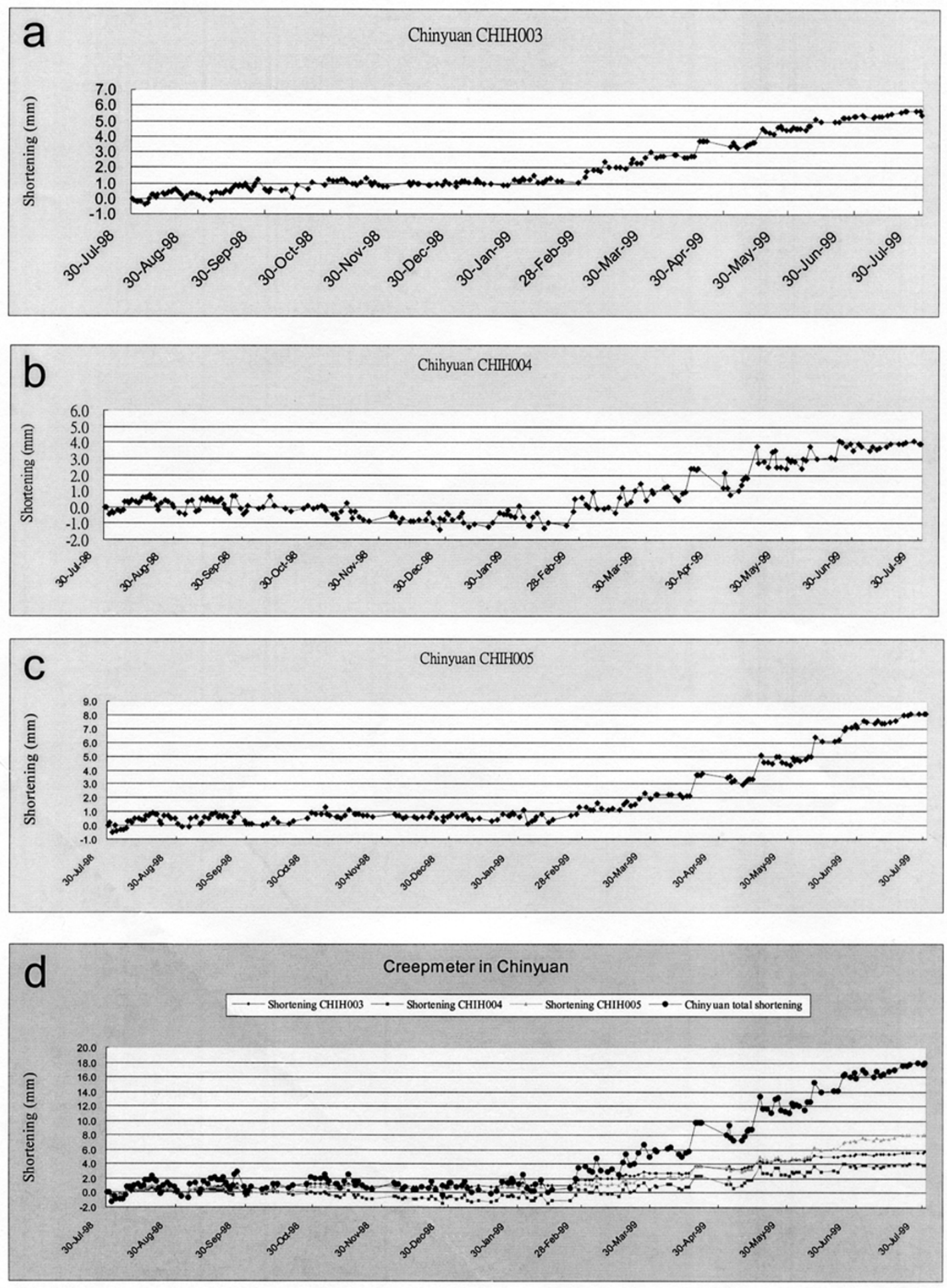

Fig. 9. One-year creep data (August 1998-July 1999) at Chinyuan village, representing by the shortening displacement of fault creep versus the time. Three creepmeters $\mathrm{CHIH003,} \mathrm{CHIH004,} \mathrm{and} \mathrm{CHIH005} \mathrm{are} \mathrm{distributed} \mathrm{along} \mathrm{a} \mathrm{water} \mathrm{channel} \mathrm{in} \mathrm{an} \mathrm{about} \mathrm{100-m} \mathrm{wide} \mathrm{fault} \mathrm{zone.} \mathrm{(a)} \mathrm{Creep} \mathrm{data} \mathrm{of} \mathrm{creepmeter}$ CHIH003. (b) Creep data of creepmeter CHIH004. (c) Creep data of creepmeter CHIH005. (d) The total shortening amount of the creepmeters represented by the sum of the data of three creepmeters.

The total shortening (sum of the shortenings of two creepmeters) is $19.4 \pm 0.3 \mathrm{~mm}$ for a year. The data indicate that the creep rate has changed through time. The shortening rate was relatively high from August to November $(29.1 \pm 0.4$ $\mathrm{mm} / \mathrm{yr})$. Then it slowed down $(5.1 \pm 0.5 \mathrm{~mm} / \mathrm{yr})$ from December to January. The creeping activities increased again from February at a rate of $16.8 \pm 0.2 \mathrm{~mm} / \mathrm{yr}$ through July. The rainfall data show that the high creep rate period coincides with a high rainfall season, whereas the low creep rate period coincides with a dry season.

Figure 9 shows the displacements due to fault creep versus time at the Chinyuan site, recorded by three creepmeters 
(CHIH003, CHIH004, and CHIH005), distributed within a $100-\mathrm{m}$ wide fault zone. The total shortening recorded by the three creepmeters is $17.3 \pm 0.7 \mathrm{~mm}$ for a year, similar to that measured at Tapo. The plot shows two periods with different types of creep. From August 1998 to February 1999 , it reveals a seemingly monthly fluctuation of creep with a very low shortening rate of about $0.6 \pm 0.4 \mathrm{~mm} / \mathrm{yr}$. There was an abrupt change in March 1999 when the fault started to move with a very high shortening rate of about $38.9 \pm 1.0 \mathrm{~mm} / \mathrm{yr}$.

In summary, the one-year results of the creepmeters in the Chihshang active fault zone show an average horizontal shortening rate of about $18 \mathrm{~mm} / \mathrm{yr}$ in Tapo $(19.4 \pm 0.3 \mathrm{~mm} / \mathrm{yr})$ and Chinyuan $(17.3 \pm 0.7 \mathrm{~mm} / \mathrm{yr})$. These results are generally consistent with the previous annual estimates at various scales, including geodetic trilaterational measurements (Yu and Liu, 1989), GPS measurements (Yu et al., 1997), and in-situ geological investigations (Lee, 1994; Angelier et al., 1997 and 1999). However, the creepmeter records bring additional information on the evolution of creep with time during the year. Such information could not be obtained earlier, because previous data acquisition was made once or twice a year (Angelier et al., 1997 and 1999).

Surface deformation measured by creepmeters can result from different sources: tectonic stress, soil creep, earth tides, human activity, and atmospheric factors (rainfall, temperature, air pressure, and so on). For this study, the creepmeters are located across the surface fractures of the active fault which has been continuously moving during the last 20 years, and the measured deformation is principally related to the tectonic movement. However, other factors, such as rainfall, temperature and so on, also play important roles which cannot be ignored. The combination of these factors may be responsible for the variations of the creep rates of the creepmeters in the Chihshang Fault area.

\section{Conclusion}

We have designed a robust rod-type creepmeter in order to monitor fault creep in active fault zones. This instrument is low-cost and its construction and installation are easy. The creepmeter is installed on the ground surface for easy access and maintenance. Details of the instrumentation have been presented in the above text. The precision of the gauge sensor is $\pm 0.01 \mathrm{~mm}$. The actual accuracy of the creepmeter records, taking all factors into account, is estimated to be $\pm 0.02 \mathrm{~mm}$ in terms of horizontal displacement due to fault creep. The most important uncertainty (or error range) comes from the temperature effect, which has been calibrated by hourly measurements. Systematic corrections are made for temperature variations based on this calibration. Observations for one year in the Chihshang active fault zone have demonstrated that this model of rod-type creepmeter is effective and reliable for near-continuous monitoring of surface movement on the active fault.

Acknowledgments. The conception of creepmeters and the site surveys were part of the Taiwan-France cooperation in earth sciences, supported by the French Institute in Taipei (IFT) and the National Science Council (NSC). The funding for creepmeter construction was obtained from Institute of Earth Sciences, Academia Sinica, National Taiwan University, Central Geological Survey, and
National Science Council grants NSC88-2116-M001-037. Helpful reviews by N. R. Goulty and T. Tsubokawa greatly improved the manuscript. Technique helps by Mr. Jiun-Hsiung Hu for development of the creepmeter are appreciated. The authors express warm thanks to Mr. S. H. Chang, Principal of the Tapo School, Mr. K. C. Jiang, Mr. I. P. Tsao, and Miss M. C. Lu, for their help in the field. This is a contribution of the Institute of Earth Sciences, Academia Sinica, IESEP2000-001.

\section{References}

Agnew, D. C., Strainmeters and tiltmeters, Rev. Geophy., 24, 579-624, 1986. Angelier, J., H. T. Chu, and J. C. Lee, Shear concentration in a collision zone: kinematics of the active Chihshang Fault, Longitudinal Valley, eastern Taiwan, Tectonophys., 274, 117-144, 1997.

Angelier, J., H. T. Chu, J. C. Lee, and J. C. Hu, Active faulting and earthquake hazard: the case study of the Chihshang Fault, Taiwan, J. Geodynamics, 29, 151-185, 2000.

Burford, R. O., Fluctuations in rates of fault creep associated with moderate earthquakes along the central San Andreas fault (abstract), Eos Trans. $A G U, \mathbf{5 7}, 1012,1976$.

Burford, R. O., S. S. Allen, R. J. Lamson, and D. D. Goodreau, Accelerated fault creep along the central San Andreas fault after moderate earthquakes during 1971-1972, in Proceedings of the Conference on Tectonic Problems of the San Andreas Fault System, vol. 13, edited by R. L. Kovach and A. Nur, pp. 268-274, Stanford Univ. Publ. Geol Sci., 1973.

Goulty, N. R. and R. Gilman, Repeated creep events on the San Andreas fault near Parkfield, California, recorded by a strainmeter array, J. Geophys. Res., 83, 5415-5419, 1978.

Goulty, N. R., R. O. Burford, C. R. Allen, R. Gilman, C. E. Johnson, and R. P. Keller, Large creep events on the Imperial fault, California, Bull. Seismol. Soc. Am., 68, 517-522, 1978.

Goulty, N. R., P. M. Davis, R. Gilman, and N. Motta, Meteorological noise in wire strainmeter data from Parkfield, California, Bull. Seismol. Soc. Am., 69, 1983-1988, 1979.

Ho, C. S., A synthesis of the geologic evolution of Taiwan, Tectonophys., 125, 1-16, 1986.

Lee, J. C., Structure et déformation active d'un orogène: Taiwan, Mem. Sc. Terre thesis, 94-17, Universite Pierre et Marie Curie, Paris, 281 pp., 1994.

Lee, J. C. and J. Angelier, Location of active deformation and geodetic data analyses: an example of the Longitudinal Valley Fault, Taiwan, Bull. Soc. Geol. France, 164, 533-570, 1993.

Mavko, G. M., Fault interaction near Hollister, California, J. Geophys. Res., 87, 7808-7816, 1982.

Nason, R. D., Measurements and theory of fault creep slippage in central California, Bull. R. Soc. N. Z., 9, 181-187, 1971.

Nason, R. D., F. R. Phillippsborn, and P. A. Yamashita, Catalog of creepmeter measurements in central California from 1968 to 1972, U.S. Geol. Surv. Open File Rep., 1974.

Raleigh, C. B., W. Stuart, and P. W. Harsh, Creep on the Calaveras fault near Coyote Lake (abstract), Eos Trans. AGU, 60(46), 890, 1979.

Schulz, S. S., G. M. Mavko, R. O. Burford, and W. D. Stuart, Long-term fault creep observations in central California, J. Geophy. Res., 87, 6977-6982, 1982.

Smith, S. W. and M. Wyss, Displacement on the San Andreas fault subsequent to the 1966 Parkfield earthquake, Bull. Seismol. Soc. Am., 58, 1955-1973, 1968.

Suppe, J., Kinematics of arc-continent collision, flipping of subduction, and back-arc spreading near Taiwan, Mem. Geol. Soc. China, 6, 21-33, 1984

Tocher, D., Creep on the San Andreas fault-Creep rate and related measurements at Vineyard, California, Bull. Seismol. Soc. Am., 50, 394-404, 1960

Tsai, Y. B., Seismotectonics of Taiwan, Tectonophys., 125, 17-38, 1986.

Yu, S. B. and C. C. Liu, Fault creep on the central segment of the longitudinal valley fault, Eastern Taiwan, Proc. Geol. Soc. China, 32, 209-231, 1989.

Yu, S. B., D. D. Jackson, G. K. Yu, and C. C. Liu, Dislocation model for curstal deformation in the Longitudinal Valley area, eastern Taiwan, Tectonophys., 183, 97-109, 1990.

Yu, S. B., H. Y. Chen, and L. C. Kuo, Velocity field of GPS stations in the Taiwan area, Tectonophys., 274, 41-59, 1997.

J.-C. Lee (e-mail: jclee@earth.sinica.edu.tw), F.-S. Jeng, H.-T. Chu , J. Angelier, and J.-C. Hu 